Article

\title{
Community-Driven Sports Events as a Vehicle for Cultural Sustainability within the Context of Forced Migration: Lessons from the Amsterdam Futsal Tournament
}

\author{
Ramón Spaaij ${ }^{1,2, *(1)}$ and Hebe Schaillée ${ }^{3}$ \\ 1 Institute for Health and Sport, Victoria University, P.O. Box 14428, Melbourne, Victoria 8001, Australia \\ 2 Department of Sociology, University of Amsterdam, P.O. Box 15508, Amsterdam 1001 NA, The Netherlands \\ 3 Research Unit Sport \& Society, Faculty of Physical Education and Physiotherapy, Vrije Universiteit Brussel, \\ Pleinlaan 2, Brussels 1050, Belgium; hebe.schaillee@vub.be \\ * Correspondence: ramon.spaaij@vu.edu.au; Tel.: +61-3-9919-4683
}

Received: 1 January 2020; Accepted: 29 January 2020; Published: 31 January 2020

check for updates

\begin{abstract}
Participation in sport can act as a means or context for enhancing the social inclusion of migrants and refugees. Research has examined if and how mainstream sport organizations' practices of engaging newly arrived migrants and refugees are effective in supporting participation in sustainable and culturally appropriate ways. Little is known, however, about the impact of community-driven sports events on sustainable participation by migrants and refugees. This paper examines this question with an analytical focus on community sustainability and the role of culture in sport event sustainability practices. The authors draw on ethnographic fieldwork with the Amsterdam Futsal Tournament (AFT), a sports event organized by Somali diaspora community members, to consider how event organizers and participants seek to promote cultural sustainability in a diaspora sport context. The fieldwork comprised 49 semi-structured interviews, participant observation before, during and after the event, and digital ethnography of event-related social media. The findings show the importance of cultural sustainability as a driver of community-driven sport sustainability practices, but also indicate how this driver is closely linked to addressing organizational and individual sustainability. The analysis demonstrates how the AFT can serve as a catalyst for the expansion of sport and community events among Somali diaspora communities.
\end{abstract}

Keywords: community sustainability; culture; sport participation; diaspora; refugees; migration; football

\section{Introduction}

Enhancing the social inclusion of refugees and asylum seekers through sport and physical activity features as a policy and program objective in a number of countries of resettlement [1,2]. The European Union, North America and Australia have witnessed significant investment in sports programs that aim to engage refugees and asylum seekers in sport and physical activity. Between 2016 and 2018, the European Commission awarded a total of $€ 3$ million across 54 projects that aimed to support the opportunities that sport and physical activity provide to promote social inclusion and wellbeing of refugees in EU member states [3].

Scientific and grey literature indicates that the experiences and outcomes of forced migrants' attempts to negotiate a sense of inclusion and belonging in sports contexts have been mixed $[2,4]$. It identifies several structural and cultural barriers to participation in sport and physical activity for migrants and refugees including unfamiliar/negative sport environments, lack of knowledge about 
participation opportunities, cost, transport, language and lack of cultural or family support for girls and women's participation. Barriers and facilitators also operate at the level of policy and practice $[5,6]$. Fundamentally, Jeanes et al. conclude that "both policy and practice in this area remain problematic due to dominant expectations of how young people from refugee backgrounds should engage in sport and also contested understandings of what resettlement and integration through sport means" [5] (p. 497). This conclusion is particularly relevant because sports providers continue to attempt to integrate or transition people with refugee backgrounds into existing mainstream sport structures that may not meet their needs or provide welcoming or inclusive environments. This is further evidenced by Northcote and Casimiro's study of a sports program for refugee-background Muslim youth, which found a disconnect between policy discourse, which prioritized participation in mainstream sport (i.e., sports clubs), and the young people's needs and aspirations, which prioritized ad hoc sports events and self-organized sport participation [7]. In a similar vein, Spaaij concludes that refugee-background youth are likely to be confronted with particular exclusionary discourses and practices within mainstream sports clubs that impede their ability to establish a sense of belonging and inclusion [8].

The abovementioned research findings reveal a need to consider a wider range of sport participation forms in relation to the social inclusion of forced migrants, beyond mainstream sports clubs and sport-based interventions. In this context, it is telling that more than 80 per cent of the published scientific research on the topic has focused on sport and physical interventions and organized team sports. In contrast, only five per cent of published research focuses exclusively on community-driven sports events, such as tournaments and festivals [2]. The latter participation form is particularly relevant in terms of its potential contribution to cultural and community sustainability, which people with refugee backgrounds may perceive as a potentially vital outcome of the social relations fostered through participation in sport [8-10]. In this paper, we draw on ethnographic fieldwork with the Amsterdam Futsal Tournament, a grassroots sports event organized by Somali diaspora community members, to consider how Somali community organizers and participants (i.e., players, referees, volunteers, and spectators) seek to sustain and promote Somali cultural sustainability in a diaspora sport context. We do so with an analytical focus on community sustainability and the role of culture related to sport event sustainability practices. We define this as sustaining a culture or heritage and developing sustainable relationships with community members, both locally and transnationally.

This paper proceeds as follows. In the next section, we examine the notions of cultural and community sustainability and their application to the sports practices of refugee-background people, with a focus on community-driven sports events. Following on from this, we discuss the methodology that guided the study. The final sections report on the research findings and reflect on their implications for scholarship in this field of study.

\section{Community Sustainability, Culture and Somali Diaspora}

In 2008, Iain Lindsey made an important theoretical intervention in the sports literature by developing a conceptual framework applicable to sustainability in sport development [11]. Synthesizing key sustainability concepts, Lindsey identified four forms of sustainability that may be addressed by sport development programs and practices: individual, community, organizational and institutional sustainability. Lindsey defines these four forms of sustainability as follows:

- Individual sustainability: longer-term changes in individuals' attitudes, aptitudes and/or behavior through involvement with the sports development program;

- Community sustainability: the maintenance of changes in the community in which the sports development program is delivered;

- Organizational sustainability: the maintenance or expansion of sports development programs by the organization responsible for their delivery;

- Institutional sustainability: longer-term changes in policy, practice, economic and environmental conditions in the wider context of the sports development program [11] (pp. 281-284). 
We would argue that these forms of sustainability are not only relevant to sport development programs, such as the aforementioned interventions targeting refugees and asylum seekers (see for example [12-14]), but may be addressed through sport participation practices more broadly, albeit in a more spontaneous (i.e., not deliberately designed), indirect or even unintended way. Our previous research suggests that community sustainability resonates particularly with the lived experiences of refugee-background people in grassroots sport $[8,9,15]$. We recognize, however, that community sustainability is closely linked with organizational and individual sustainability, and may, in part, be driven by the same, or similar, processes. We will explore this interlinkage in detail in the presentation of our research results later in this paper.

Some further conceptual work is needed to translate the notion of community sustainability to the context of sport as means for the social inclusion of migrants and refugees. The reference to "community" requires clarification due to its contested and elusive nature [16], including in relation to "community sport" [17,18]. Lindsey's definition "leaves open the possibility that communities could be interpreted geographically, culturally (in the case of a sporting community) or organizationally (in the case of the community of agencies)" [11] (p. 283). For the present purpose, we interpret community primarily through a cultural lens to align with the way it has been predominantly used within studies of migration, sport and inter/multiculturalism [19-22]. In doing so, we connect community sustainability with the notion of cultural sustainability, which features internationally as a pillar of community sustainability and wellbeing [23,24], including in relation to migration and diasporas [25].

The conceptual relationship between culture and sustainability remains vague in discourse and practice. Duxbury and Jeannotte argue:

If the social dimension of sustainability has often been missing from sustainability discourse and practice, the inclusion of culture within conceptual and planning frameworks for long-term community wellbeing and sustainability has tended to be even more vague and fractured. As a result, cultural considerations tend not to be integrated into sustainability initiatives in a widespread or consistent way [23] (p. 1).

There are multiple ways to consider culture in sustainability, which cover different political and normative positions [24]. Soini and Birkeland identify seven "story lines" in the representation of culture in cultural sustainability discourses: heritage, vitality, economic viability, diversity, locality, eco-cultural resilience, and eco-cultural civilization [24]. The heritage and cultural vitality story lines frame cultural sustainability as the continuity of culture. They "represent culture as tangible or intangible cultural capital to be preserved for future generations and to be used in the creation of collective identities and social and cultural inclusion" through, for example, the arts or sport [24] (p. 219). The economic viability narrative evokes liberal or neoliberal ideas of culture to construct it as a resource to be "used for its instrumental promotion in markets to serve the economic viability of places and communities, particularly through tourism and the creative economy" [24] (p. 219). The diversity and locality story lines emphasize cultural sustainability "not only in terms of the inclusion of various perceptions and values but also with regard to the cultural rights of cultural groups" [24] (p. 219). These two story lines "seem to share a communitarian political ideology, where cultural development is to be treated in the specific and local cultural context, a community, which requires the social and cultural inclusion of people in the planning and decision-making that concerns their lives" [24] (pp. 219-220). Finally, the eco-cultural resilience and eco-cultural civilization story lines "seek better integration of human and natural systems, reconnection, even a paradigm shift, seeing sustainable development through ecological lenses. They construct an ecological turn of culture in the way we are being and behaving in the world" [24] (p. 220).

In this paper, we view these clusters of meaning from the vantage point of a particular self-identified community: the Somali diaspora community. Diaspora communities are not static or monolithic, but dynamic constructions. Clifford views diasporas as being composed of "displaced peoples who feel (maintain, revive, invent) a connection with a prior home" [26] (p. 255). Diasporas comprise people who are physically dispersed but linked through shared allegiances and practical connections to a 
common "homeland" [27]. Diaspora formation and maintenance involves the negotiation of a shared sense of transnational identity, provision of transnational care and support, and the maintenance of cultural heritage and language. Sport practices such as community-driven sports events or leagues can contribute to this process of diaspora formation and maintenance $[9,19,20,28-30]$. In this paper, we focus on one such event: the Amsterdam Futsal Tournament (AFT), a transnational sports event that is organized by Dutch and European Somalis to foster diasporic ties and promote cultural sustainability.

Community organizations have the potential to play an important role in promoting sustainable development and cultural sustainability across Somali diaspora communities [31]. To date, it appears that this potential has not been fully realized due to, for example, internal division and tribal politics [32,33]. In the case of AFT, the event organizer is the Somali community organization Himilo Relief and Development Association (HIRDA), with the aim "to empower and improve the integration of young Somali diaspora in Europe through sports, dialogue and network building" [34]. HIRDA is a non-profit organization founded in 1998 by members of the Somali diaspora in the Netherlands. It works closely with diaspora organizations, community organizations and local communities to contribute to the development of Somalia and the global Somali diaspora [35].

Somali community organizations' efforts to promote cultural sustainability, alongside other objectives, should be viewed within the context of ongoing displacement, resettlement and settlement of people who identify as Somali. By 2015, the total number of people born in Somalia but living outside the country had reached two million [36]. An estimated 1.5 million people are internally displaced in Somalia and nearly 900,000 are refugees in the near region, especially in Kenya, Yemen and Ethiopia [37]. The European Union, Norway and Switzerland are home to 14 per cent of the world's Somali migrant population. Destination countries within Europe have changed over time. In 2015, Germany and Sweden received about half of the Somali asylum seekers in Europe. In earlier years, the Netherlands and Italy were relatively common destinations for Somali asylum seekers [36]. The total number of Somali-background people currently registered in the Netherlands, where the AFT is held, is 39,947 [38]. This number fluctuates, due in part to subsequent onward migration [39].

Culture and community are dynamic; their meanings and boundaries change in time and space. There is sizeable literature on the ways in which Somali migrants express themselves culturally in hybrid ways [40-43]. For example, in her study of Somali women in London and Toronto, Hopkins concludes that in resettlement contexts, "the Somaliness with which they previously identified was no longer the Somaliness they felt accurately represented them, even though they adhered to many aspects of being Somali, such as language and dress, and felt a sense of belonging to the local Somali community in London or Toronto" [44] (p. 529). In a similar vein, yet focusing specifically on sport, Spaaij found that the cultural belonging constructed by Somali Australian youth in sports clubs was hybrid, dynamic and situational, operating at varying scales of experience from the sports team and local community through to the global Somali diaspora and cosmopolitan belonging [8]. There is, in this sense, no quintessential "Somali culture". However, as we will show in the remainder of this paper, a number of common cultural reference points highlighted in the literature resonate strongly with the narratives of the AFT participants. Language is considered "one of the most important aspects of Somali culture" and "in creating Somaliness and maintaining contact with Somalia" [44] (p. 529). Family/kinship, faith (Islam), generosity and hospitality are also considered key aspects or virtues of Somali culture e.g., [40]. These cultural facets are reflected in, for example, the importance of the Somali language at the AFT, local organizers' and participants' hospitality towards extra-local visitors, but also in religious and cultural restrictions, or sensitivities, regarding women's participation in the event (see also $[9,15]$ ). In the next section, we discuss the research methods used to investigate the cultural sustainability practices within AFT and their impact on the Somali diaspora in the Netherlands and beyond. 


\section{Methods}

Our methodological orientation is characterized by a concern for lived experience, meaning and process, in order to "help capture the complex and multi-faceted process through which individuals experience beneficial [or detrimental] social outcomes from sport" [45] (p. 1188). Through qualitative investigation, the study upon which this paper builds sought to capture the voices, experiences and meaning-making processes of AFT participants in relation to the sport event's cultural sustainability practices and outcomes. Below we discuss the qualitative research methods used in this study.

\subsection{Data Collection}

The empirical data were collected before, during and after the AFT event in 2015, and supplemented with follow-up data. The study combined face-to-face interviews, participant observation and, to a lesser extent, digital ethnography. The interview strand involved semi-structured interviews with 49 participants who performed a range of roles: players, coaches, referees, volunteers, spectators, and representatives of Somali community organizations and local government departments. Forty-three of these individuals directly participated in AFT as players, coaches, referees, volunteers or spectators. Multiple strategies were used to recruit participants for the study. Community-based information sessions were held before and during AFT to explain the purpose and nature of the research and to invite people to participate in the study. In addition, the researchers directly approached team captains and coaches with a request to consider their teams' participation in the study. The interview guide was developed in close consultation with a Dutch Somali community worker, who served as a research consultant on the project, as well as with HIRDA representatives to ensure cultural appropriateness of the research questions and instruments (e.g., a focus on oral methods). The interview questions were designed to elicit participants' perceptions, experiences, relationships and actions. The interview schedule covered a range of topics such as respondents' sports experiences, sense of belonging and identity, cultural heritage and integration experiences. The interviews were held in the respondent's preferred language, which in most cases was Dutch (36 respondents) but also included English (10 respondents) and Somali (3 respondents). The interviews were conducted at two indoor sports facilities in Amsterdam, at local cafés, and at Somali community organizations located in different parts of Amsterdam. Interviews lasted between 30 and 90 minutes; they were audio recorded and transcribed verbatim.

The second, parallel strand of this study involved observation and participation in the sporting lives of respondents, with a particular focus on their engagement with AFT. The nature of the event (two full days only) limited the opportunity to conduct longer-term observation of participants' engagement with the event. To overcome this limitation, in addition to two days of full-time observation during AFT, the researchers conducted preliminary observations of participating individuals' and teams' training and preparatory sessions in the weeks leading up to the tournament. Initial access to these sites was gained through the research consultant, who introduced us to players, coaches and volunteers, and who provided guidance and positive recommendation throughout the fieldwork. The observation protocol, designed in consultation with HIRDA, sought to capture participants' behaviors, interactions, language use, rituals, as well as other indicators of aesthetic formation.

Finally, we collated and analyzed the social media activity that was produced specifically in relation to AFT. The two main social media platforms for the event are Facebook and YouTube, where organizers, participants and community members can post and consume text, images and videos. Examples include messages posted on the HIRDA and AFT Facebook pages to express opinions or feelings about the event, photographs of the event, and video footage produced by HIRDA volunteers that features both match coverage and vox pop interviews with participants. 


\subsection{Data Analysis}

The interview transcripts, field notes and social media products were analyzed using thematic analysis techniques. The research team (the first author and research assistant) read the transcripts, field notes and social media messages, and coded passages of text firstly using an open (or initial meaning code) and secondly, an axial (or categorization of open codes) coding scheme. For example, the statement "You know it's just, as my friend said, the support is not coming from the parents, and it's not coming from the community we are living in. The community is not expecting you to become a footballer or an athlete", would initially be coded as "Barriers to sport participation". After similar statements related to the theme Barriers were open coded, all the statements under this code would then be coded a second time to further categorize the statement. In this example, the statement would be further coded under the axial code "Lack of parental/community support". Dialogue among the researchers resulted in intersubjective agreement on the interpretation of the identified passages and codes.

\subsection{Ethics}

A recent review of the literature on sport and forced migration concluded that "limited discussion is afforded to ethical challenges and considerations within the current literature" and that "critical reflection on the challenge of constructing ethical relationships in this field of research is required" [2] (p. 15). In this study, strategies were designed to forge and negotiate ethical relationships with research participants. As noted, we contracted a Dutch Somali community worker to assist in the design and implementation of the study as a research consultant. We worked closely with the community worker and with HIRDA representatives to ensure the research design and implementation met community standards and expectations, and embodied the necessary cultural sensitivity and appropriateness. The aforementioned language flexibility enabled respondents to express themselves in the language that they felt most comfortable with during the interviews. Another strategy that was employed in this study was an iterative model of consent, whereby consent was an ongoing negotiation [46]. Through ongoing engagement with the participating teams, volunteers and associated community organizations, we sought to enable participants to play a more active role in shaping the research in a way that was responsive to their needs and respects their concerns and values. This included, for example, ongoing opportunities to raise research questions and issues that participants deemed meaningful to them (e.g., self-organizing capacity, gender) as well as ongoing consideration of how the research was shared and disseminated.

\section{Findings}

The research methods discussed in the previous section yielded insights into the cultural and community sustainability practices surrounding the Amsterdam Futsal Tournament. The findings of this study reveal cultural sustainability primarily through two of the seven clusters of meaning conceptualized by Soini and Birkeland: heritage and cultural vitality, and diversity and place [24]. We identify three distinct, yet inter-related, themes associated with these two clusters of meaning in relation to cultural sustainability. These themes are:

- $\quad$ Sport event sustainability practices;

- Performing and connecting with Somali culture and identity;

- Ripple effects on self-organizing capacity.

Below, we discuss each theme and explore their links to, inter alia, Lindsey's four forms of sustainability [11]. 


\subsection{Sport Event Sustainability Practices}

The local and transnational actors that work together to organize AFT recognize the important role of the Somali diaspora in contributing to sustainable development in Somalia. They believe that "the added value of migrants to their homeland is still not fully acknowledged" and that building partnerships between development actors and diaspora will lead to more efficient and effective support for sustainable development [47] (p. 1). This belief has led HIRDA and its partner organizations to search for innovative and sustainable ways to utilize the resources of diaspora members to contribute to the development of Somalia. This mission covers the broad spectrum of economic and social development, but it is reflected in the organizations' efforts to promote cultural sustainability. HIRDA initially focused its efforts on the development of Somalia. The economic viability story line of "diaspora as a resource" is evident in the way HIRDA frames this challenge: "There are around 770,000 Somali refugees dispersed around the world; the vast majority of which is still strongly involved in their homeland. The remittances that these migrants send to their home country have been estimated [at] between US\$750 million and a billion dollars annually, making remittances the main source of income for Somalia and considerably larger than the amount of international aid Somalia receives" [47] (p. 1). However, as we will show below, its work in the area of sport aligns primarily with the story lines of heritage and cultural vitality, and diversity and place. The economic viability story line is largely confined to efforts aimed at safeguarding the event's organizational and financial sustainability.

From 2003, HIRDA became active in Somali youth integration programs in the Netherlands. Dutch Somali youth, especially young males, voiced their demand for sports activities, leading HIRDA to adopt sport as part of its programs in order to enhance young people's capabilities and their pathways to employment and education. Hasan, a Somali youth worker in his 60s, explains:

There was a need, a massive need for the young people here. They said: "We have lots of teams, can you organize for us please?" And so the Somali youth, the only thing they know how to do, once they are not in their home, is to play sports.

While the young people's main interest may have been "sport for sport's sake", from a sustainable development perspective, sport offered HIRDA and its partners a "hook" to engage young people, especially young males, in projects aimed at enhancing their capabilities and social inclusion. From the outset, there was an intention to develop the Dutch Somali diaspora community and its members through sport, rather than simply increasing sport participation levels amongst young people in the community. The sports activities offered by HIRDA and other Somali community organizations contain elements of both "sport plus" and "plus sport" [48]. "Sport plus" involves projects in which traditional sport development objectives of increased participation and development of sports skills are emphasized, even though these objectives are "rarely the sole rationale and very rarely the basis for external investment and subsequent evaluation" [48] (p. 71). "Plus sport" projects, on the other hand, give primacy to social, educational or health objectives-in the case of AFT, social inclusion/integration and sustainable development objectives. For example, in addition to the futsal competition, AFT features panel debates on the current situation and future of Somalia, as well as the conditions and experiences of the Somali diaspora community. It also feeds into a number of other programs designed to build protective factors and resilience among Dutch Somali youth and new arrivals.

In 2005, HIRDA launched AFT with funding from the International Year of Sport and Physical Education. AFT is held twice a year-a 24-team winter event and a smaller, 16-team summer tournament. HIRDA has been able to achieve a level of financial and political independence in the way it organizes the event. It receives a small subsidy from the Municipality of Amsterdam but most of the expenditure is covered by registration fees paid by the participating teams ( $€ 85$ per team in 2015 ). HIRDA has a considerable membership worldwide that contributes to its programs. HIRDA relies, in part, on the in-kind contributions of volunteers who play a pivotal role in the delivery of AFT.

AFT's marketing strategy aims to raise interest in the event among not only prospective participants but also diaspora members across the world. The website, Facebook page and YouTube livestream 
enable people to digitally engage with the event. A selection of matches and social events (e.g., panel debates and interviews with prominent visitors) is broadcast via the livestream and archived on the event website. This strategy has been successful in the sense that the event has been growing steadily over the years, attracting participants and spectators from various parts of Europe including Scandinavia, Switzerland and the United Kingdom. At one point, the tournament had 36 registered teams, which was considered too difficult to manage with the existing resources.

The diversity story line of cultural sustainability identified by Soini and Birkeland [24], which highlights the inclusion of various perceptions and values, is clearly present in the respondents' perceptions of AFT's promotion and marketing, especially among female interviewees who flagged gender disparity. This story line, and the tensions it reveals, reminds us that culture and community are not monolithic or static. The primary focus of the marketing strategy is the men's futsal tournament. In contrast, the women's basketball tournament, that has been organized occasionally as part of AFT, receives far less promotion. HIRDA acknowledges that despite its commitment to include women in AFT, it has been challenging to sustain the women's competition, primarily due to the limited number of volunteers and the financial costs of overnight accommodation for participants from outside of Amsterdam. Female participants, who are recruited into AFT through word of mouth, express the benefits they accrue from participating in the basketball tournament, but they also reveal the gender norms that constrain participation. For example, Hala (female volunteer, 20s) reports:

It was one of those rare moments where we met each other and it was a temporary reality escape. We went to play basketball and regardless of how good you were, it was about the connection we had. I am very disappointed that it has been so difficult to sustain. [ ... ] Because when I see a Somali girl play basketball, it's fun. It's not something you encounter in everyday life, that you are playing basketball against Somali girls. It's not something that is being encouraged. That has a lot to do with the culture. Girls don't play sport, the old-fashioned belief. This belief will fade, but it's still there.

During the interviews, female participants expressed that they would like to see more attention and promotional activities being afforded to the women's event in order to raise its visibility and increase the participation of girls and women in AFT. For example, Nadia (volunteer, 20s) suggests:

We have to make it more visible. I know about it because I worked at HIRDA as a volunteer. But the promotional materials are aimed at the men. You don't have to feature women on the posters, but you can bring it to the fore a lot more and integrate it into the marketing. The event is mainly focused on futsal, which is the most popular, and is made up for 80 per cent of men's teams. I get that, but it would help if we bring it to women's attention more. [ ... I I think it's great that it is being filmed [for the livestream] because it shows you Somali women playing sport. You almost never see that. It attracts more attention that way.

These comments suggest that, in their attempts to sustain the AFT, the organizers cater primarily to males and may thus (inadvertently) reproduce gendered cultural norms. The narratives of female participants further reveal a "changing sense of their own Somaliness" [44], under influences of migration and integration, especially among those participants who were educated in the Netherlands.

The diversity story line is also evident in the organizers' attempts to facilitate social interaction, connectedness and two-way learning between established Dutch Somalis and recent arrivals (so-called nieuwkomers). For new male arrivals, playing informal sport can provide a low-threshold context for meeting new people, learning about life in a new country, and a sense of continuity in their lives during a time of change and resettlement [48-50]. Somali youth worker Mohamed (male, 30s) explains how participating in AFT provides an opportunity for "getting to know different people, sharing news and experiences. [ ... ] Some are new arrivals, others were born in the Netherlands or elsewhere in Europe. That kind of information sharing is very important. [ ... ] It is valuable for new arrivals. They mainly speak Somali and some of them don't speak Dutch. Old and new arrivals mix at AFT and they get to know each other". Hala similarly reports: 
The past few years we have seen many new arrivals. [ ... I It's easier to help them when you speak the same language and when you understand where they come from. [...] That can be an important source of support, that they feel safer and also to participate in sport and to get to know many people who can teach them the [Dutch] language and make friends. You simply feel better understood by someone who knows where you come from. I have many people in my environment who are new arrivals and I always try to motivate them.

From a cultural sustainability perspective, it is important to note that this social learning and exchange process works both ways. Several participants explained that they had learned cultural knowledge and customs from foreign visitors to AFT and new arrivals. It is to this cultural exchange and its impact on participants' perceived connection with Somali culture and identity that we now turn.

\subsection{Performing and Connecting with Somali Culture and Identity}

One of the most meaningful aspects of AFT is that it provides a context within which participants can experience a sense of belonging to the Somali diaspora community and actively engage with (diasporic) Somali culture and heritage. For the duration of the tournament, the sports centres are transformed into veritable diasporic Somali cultural spaces where elements of Somali culture can be readily consumed. Respondents frame this experience in terms of the continuity and transmission of culture and its deployment in the creation and maintenance of collective identity [24] (p. 219). Cultural heritage is represented in various ways at AFT. Somali is the main language spoken during the event and also is the official language. Several participants wear Somali football uniforms. There are Somali musical performances, poetry, and book displays. Traditional Somali dishes are served and some visitors wear traditional Somali clothing.

For many respondents, cultural vitality is a major motivating factor for attending the event, along with the social aspect of AFT. As Nadia argues:

It's something that is ours. I believe we need something to hold on to. Something that only belongs to Somalis, that's simply more pleasant. Everything else in the Netherlands is mixed, every club I know has Dutch people. So let's keep this event for Somalis. I cannot really justify it, it's just a feeling.

In a similar vein, another interviewee expresses:

It would also be okay if it was a mixed event, but I am not sure if I would attend it. But because it is focused on Somali people I do attend. There isn't much being organized for Somalis in general, so it's great that this event focuses specifically on Somalis (Fatuma, female, 20s).

Although Nadia downplays her experience as "just a feeling", the scientific literature provides an evidence base for it. Sporton and Valentine, for example, found that "a sense of 'belonging' in a country develops where a community has a sense of security and space to define its own identity beyond or alongside narrow prescriptions of national identity" [41] (p. 19). AFT provides such a space, albeit temporarily. The importance thereof for Somali youth in diaspora should not be underestimated [42]. A Somali community elder (male, 60s), who mentors and coaches several European Somali young men and women, explains this importance as follows:

Questioning identity is very, very strong for lots of young Somalis. For some of them it becomes really painful to understand or accept who they are, because one country gave me everything that I have now, and another one I came from. [ ... I I think this tournament is one of those things that can make that process easier, especially some of the debates that happened last night... There was one was born here, he's never seen Somalia; one who came from Somalia young then grew up most of his life in Sweden, so he's kind of Swedish, and that's his feeling; and some who recently came to Somalia or visited Somalia. I hope lots of the others will listen and could learn something from it. [ ... ] If they realize their identity and accept that they can be different people, and wear different hats at different times, that will make it easier for them. So identity, the questions are not going to end now, it's going 
to continue for a long time. Even for me, sometimes I don't know which of my hats I'm wearing, and it's something that will stay with them probably for the rest of their lives.

Several participants made direct reference to their identity and cultural heritage. They appeared to be more consciously aware and confident of their Somali identity and heritage during AFT. They argued that their engagement with and experience within the tournament affected their sense of belonging to, and roots in, their "homeland" and Somali diasporia communities [9]. For example, male referee Abdi (male, 20s) describes how "it makes me to feel more Somali. Yeah. And like I'm involved here... with other people who also speak Somali as their first language. It makes me proud". Hala similarly reports: "I am Dutch, I was born here, but it is still important to me to know where I come from. Because we are so dispersed it is difficult to find anyone who reminds you of your roots. I believe that is a very essential thing". Another respondent adds: "The mentality that I used to have was, like, Somali music and culture is annoying. [ ... ] But now I think: it's your culture. You have to know it. And I immerse myself in it. It's a part of yourself, it's a piece of your roots. It's important to know yourself, who you are" (Aicha, female, 20s).

These findings indicate the interplay between cultural sustainability, at a collective level, and individual sustainability. The latter refers to "longer-term changes in individuals' attitudes, aptitudes and/or behavior through involvement with the sports development program" [11] (p. 282). The results show self-reported changes in participants' sense of belonging to the Somali diaspora community and their sense of Somaliness. However, on the basis of currently available data, it is not possible to draw any firm conclusions regarding the longer-term effect of these changes on individual participants. In the next section, we discuss the more collective elements of this process, which suggest the intersection between cultural and organizational sustainability within the context of AFT.

\subsection{Ripple Effects on Self-organizing Capacity}

The Amsterdam Futsal Tournament serves as a node in a dispersed transnational network of self-identified Somalis. Influenced by distant and local linkages with other Somalis and through their cultural and social experiences in their countries of residence, some diasporic Somalis have been active in a range of diasporic sports events in countries such as the Netherlands, Sweden, Finland, UK, Switzerland and Canada. This experience has augmented their capacity to organize similar sports events in their own localities of residence. The findings show that participation in AFT can have an inspiration effect in this regard. AFT co-founder Mohamed (male, 50s) notes:

When we started this tournament, some people thought we wouldn't be able to organize it. Then they witnessed that it could be done. They learned that engaging young people to come out and organize events works. [ ... ] When I visit other countries like America, Canada and European countries, they ask me to help organize tournaments there. We have many people doing this now.

HIRDA board member Hasan similarly reflects on the example that AFT sets:

Some young people returned to Somalia and started to organize sport there. We have seen self-organizing by young people in [Dutch] cities like Utrecht, Venray and others. At AFT they see how they can support each other and organize similar events in their own localities. They are organizing themselves more consciously and have good discussions about this. The youth are proud to see that Somalis can self-organize. They had lost that hope because the community is very fragmented. So AFT has a kind of example or mobilization function.

The empirical data substantiate this argument. The aforementioned community elder is a case in point:

We hold competitions [in the UK], we hold things, but not up to the precision or profession of AFT. I think they plan it a year in advance, they... you know and they do everything to just be... well organized. So let me accept that in that organization they're better. I also once took part in organizing 
things in North America, so I did live in many different places. And I think this is the one specialty of HIRDA, that they are well organized. The one thing I've learnt is that there's nothing called impossible, that anything could be done, because if HIRDA can do this, then you know anyone, anywhere, they could organize themselves to do something similar.

Several participants recount similar stories. For example, the captain of one of the Finnish teams that participates reports:

I was talking with our coach and he was like "maybe someday we can organize tournament like this one back in Finland". Because in Finland we have big Somali communities nowadays, like in Netherlands and Amsterdam. So why don't we show how we got experience here and we'll take it, all the things we have learnt here. And it's not that big a thing you know. We have to make good contacts with the teams from different European countries. It's a good opportunity to learn about how they organize in teams, and making contacts from here (Roble, male, 20s).

A Dutch Somali volunteer who is passionate about athletics adds:

I organized athletics events twice. People from the UK contacted me to ask if I could help them organize such events over there. In Sweden, Somali people asked me how I did it because they want to organize events too. The contacts with Somalis in other countries become closer like that.

A few women expressed in the interviews that they took notice of the self-organizing potential present within their communities and would like to act on it. AFT volunteer Nadia reflects on this unrealized potential as follows:

What I see in my city, we have a large group of new arrivals. Every Wednesday they organize a football match as a group. They completely self-organize. Guys from different neighbourhoods come together and play. That's their own grassroots initiative. For them AFT is a big match. If there was a similar supply for girls, then we [the girls and women] would be more likely to say: "Okay let's play football. Let's go and do something fun together". That it extends beyond AFT. If we had a bigger group then there will always be a few who say "Hey let's play this week". The guys always have a big group. They organize it really well, actually.

These lived experiences of self-organizing capacity that is influenced by AFT reveal the intersection between cultural (or community) sustainability and organizational sustainability. For those involved in AFT, cultural sustainability is closely linked to addressing organizational sustainability, which Lindsey defines as "the maintenance or expansion of sports development programs by the organization responsible for their delivery" [11] (p. 283). As the results show, in the case of AFT it is not so much the maintenance or expansion of the administering organization, i.e., HIRDA, but rather the grassroots mobilization and capacity building among Somali diapora community members that is critical to organizational sustainability. In this regard, HIRDA's hosting of AFT can be seen to have had a ripple effect across various sections of the Somali diaspora community, with increased levels of self-organizing capacity and community-based action in relation to diasporic sports events.

\section{Discussion and Conclusions}

In this paper, we have drawn on ethnographic fieldwork with a grassroots sports event organized by Somali diaspora community members to consider how event organizers and participants seek to sustain and promote cultural sustainability in a diaspora sport context. The study findings highlight a number of issues that can inform contemporary scholarship on the relationship between sport, migration and sustainability. The first conclusion is that within the particular context of community-driven sport in the Somali diaspora, cultural sustainability is framed and practiced primarily through two of the seven clusters of meaning identified by Soini and Birkeland, namely heritage and cultural vitality, and diversity and place [24]. The economic viability story line can be found in the broader development 
work undertaken within the diaspora, but less so within AFT. The eco-cultural story lines are absent from the participant narratives captured in the research.

The results indicate the importance of cultural sustainability as a key driver of the sustainability practices surrounding AFT. The "continuity of culture" narrative is particularly dominant within organizer and participant narratives, as revealed through their stories about performing and connecting with Somali culture and identity, including their (temporary) heightened sense of belonging to Somalia and to the global Somali diaspora. However, the longer-term effects of participation in AFT on this dimension of cultural sustainability would need to be measured using longitudinal data, notably how the participants have interacted with Somali culture after they participated in AFT. The absence of this data is a limitation of the current study, which reflects the dearth of longitudinal research in the broader literature on sport and forced migration [2]. We thus echo the recent call for "scholars in this field of study consider how longitudinal designs can be applied effectively in their work" [2] (p. 14).

At the same time, this study suggests that while cultural sustainability is an important motivating factor, it cannot be viewed in isolation from other forms of sustainability. In particular, the results highlight that cultural sustainability practices are closely linked to addressing organizational and individual sustainability. The interplay between cultural and organizational sustainability is shown most clearly in the community capacity building outside HIRDA as part of organizational and community sustainability. Through self-organization, Somalis scattered across different countries have initiated sports events in their own localities in ways that contribute to the maintenance and performance of culture. Participants report "feeling more Somali"; that is, more closely connected to Somali culture and identity. The findings suggest that indicators of belonging, such as dress and language, come to hold new and increased value within the AFT context [44]. The longer-term impact of participation in AFT or similar events elsewhere in the global Somali diaspora on individual sustainability is yet to be ascertained, however. The same limitation regarding the absence of longitudinal data applies. Herein lies an important direction for future research. Moreover, the results show that individual sustainability is gendered in the sense that girls and women experience restricted access to playing opportunities at AFT, which has adverse consequences for their level of involvement in the event as athletes (as opposed to volunteers).

We have sought to show in this paper that cultural sustainability, defined as sustaining a culture or heritage and developing sustainable linkages with community members, can be usefully adopted as an analytical framework for the study of the nexus between sport, migration and sustainability. The local and transnational linkages and practices discussed in this paper seek to promote and celebrate an increased sense of Somaliness within the dispersed sports and social networks in the global Somali diaspora. In this context, sport (and football in particular) acts as a meaningful, yet gendered, form of, and resource for, diasporic culture production and consumption.

Author Contributions: Conceptualization, R.S.; investigation, R.S.; methodology, R.S.; project administration, R.S.; writing - original draft, R.S. and H.S.; writing - review \& editing, R.S. and H.S. All authors have read and agreed to the published version of the manuscript.

Funding: This research received no external funding.

Acknowledgments: We are grateful to Jora Broerse for her major contributions to the data collection and analysis for the research. Her contributions were vital to the conduct of this research. We thank the Himilo Relief and Development Association and the research participants for their generous contributions to this study.

Conflicts of Interest: The authors declare no conflict of interest.

\section{References}

1. Spaaij, R.; Oxford, S. SDP and forced displacement. In Routledge Handbook of Sport for Development and Peace; Collison, H., Darnell, S., Giulianotti, R., Howe, P.D., Eds.; Informa UK Limited: London, UK, 2018; pp. 385-395. 
2. Spaaij, R.; Broerse, J.; Oxford, S.; Luguetti, C.; McLachlan, F.; McDonald, B.; Klepac, B.; Lymbery, L.; Bishara, J.; Pankowiak, A. Sport, Refugees, and Forced Migration: A Critical Review of the Literature. Front. Sports Act. Living 2019, 1, 47. [CrossRef]

3. Results Published: Call for Proposals "Sport as a Tool for Integration and Social Inclusion of Refugees". Available online: https://ec.europa.eu/sport/news/2018/results-published-call-proposals-sporttool-integration-and-social-inclusion-refugees_en (accessed on 14 May 2019).

4. McDonald, B.; Spaaij, R.; Dukic, D. Moments of social inclusion: asylum seekers, football and solidarity. Sport Soc. 2019, 22, 935-949. [CrossRef]

5. Jeanes, R.; O'Connor, J.; Alfrey, L. Sport and the resettlement of young people from refugee backgrounds in Australia. J. Sport Soc. Issues 2015, 39, 480-500. [CrossRef]

6. Anderson, A.; Dixon, M.A.; Oshiro, K.F.; Wicker, P.; Cunningham, G.B.; Heere, B. Managerial perceptions of factors affecting the design and delivery of sport for health programs for refugee populations. Sport Manag. Rev. 2019, 22, 80-95. [CrossRef]

7. Northcote, J.; Casimiro, S. A critical approach to evidence-based resettlement policy: Lessons learned from an Australian Muslim refugee sports program. Tamara J. Crit. Organ. Inq. 2009, 8, 173-185.

8. Spaaij, R. Refugee youth, belonging and community sport. Leis. Stud. 2015, 34, 303-318. [CrossRef]

9. Spaaij, R.; Broerse, J. Diaspora as aesthetic formation: community sports events and the making of a Somali diaspora. J. Ethnic Migr. Stud. 2019, 45, 752-769. [CrossRef]

10. Spaaij, R. Sport and Social Mobility: Crossing Boundaries; Routledge: London, UK, 2011.

11. Lindsey, I. Conceptualising sustainability in sports development. Leis. Stud. 2008, 27, 279-294. [CrossRef]

12. Mohammadi, S. Social inclusion of newly arrived female asylum seekers and refugees through a community sport initiative: The case of Bike Bridge. Sport Soc. 2019, 22, 1082-1099. [CrossRef]

13. Hashimoto-Govindasamy, L.; Rose, V. An ethnographic process evaluation of a community support program with Sudanese refugee women in western Sydney. Heal. Promot. J. Aust. 2011, 22, 107-112. [CrossRef]

14. Forde, S.D.; Lee, D.S.; Mills, C.; Frisby, W. Moving towards social inclusion: Manager and staff perspectives on an award winning community sport and recreation program for immigrants. Sport Manag. Rev. 2015, 18, 126-138. [CrossRef]

15. Spaaij, R. Beyond the playing field: Experiences of sport, social capital, and integration among Somalis in Australia. Ethn. Racial Stud. 2012, 35, 1519-1538. [CrossRef]

16. Delanty, G. Community, 2nd ed.; Routledge: London, UK, 2009.

17. Schaillée, H.; Haudenhuyse, R.; Bradt, L. Community sport and social inclusion: international perspectives. Sport Soc. 2019, 22, 885-896. [CrossRef]

18. Torchia, D. Creating and managing community in a community football club. Manag. Sport Leis. 2019, 1-20. [CrossRef]

19. Burdsey, D. Contested conceptions of identity, community and multiculturalism in the staging of alternative sport events: a case study of the Amsterdam World Cup football tournament. Leis. Stud. 2008, 27, 259-277. [CrossRef]

20. Burdsey, D. British Asians and Football: Culture, Identity, Exclusion; Routledge: London, UK, 2007.

21. Thangaraj, S. Desi Hoop Dreams: Pickup Basketball and the Making of Asian American Masculinity; New York University Press: New York, NY, USA, 2015.

22. Smith, R.; Spaaij, R.; McDonald, B. Migrant integration and cultural capital in the context of sport and physical activity: A systematic review. J. Int. Migr. Integrat. 2019, 20, 851-868. [CrossRef]

23. Duxbury, N.; Jeannotte, M.S. Including culture in sustainability: An assessment of Canada's Integrated Community Sustainability Plans. Int. J. Urban Sustain Dev. 2012, 4, 1-19. [CrossRef]

24. Soini, K.; Birkeland, I. Exploring the scientific discourse on cultural sustainability. Geoforum 2014, 51, $213-223$. [CrossRef]

25. Naguib, S.-A. Museums, diasporas and the sustainability of intangible cultural heritage. Sustainability 2013, 5, 2178-2190. [CrossRef]

26. Clifford, J. Routes: Travel and Translation in the Late Twentieth Century; Harvard University Press: Cambridge, MA, USA, 1997.

27. Clifford, J. Diasporas. Cult Anthropol 1994, 9, 302-338. [CrossRef]

28. Werbner, P. "Our blood is green": Cricket, identity and social empowerment among British Pakistanis. In Sport, Identity and Ethnicity; MacClancy, J., Ed.; Berg: Oxford, UK, 1996. 
29. Joseph, J. A Diaspora Approach to Sport Tourism. J. Sport Soc. Issues 2011, 35, 146-167. [CrossRef]

30. Joseph, J. Culture, community, consciousness: The Caribbean sporting diaspora. Int. Rev. Sociol. Sport 2014, 49, 669-687. [CrossRef]

31. Abdullahi, A.M. Critical Realism, Somalia and the Diaspora Community; Routledge: London, UK, 2014.

32. Griffiths, D. Somali and Kurdish Refugees in London: New Identities in the Diaspora; Ashgate: Aldershot, UK, 2002.

33. Hopkins, G. Somali Community Organizations in London and Toronto: Collaboration and Effectiveness. J. Refug. Stud. 2006, 19, 361-380. [CrossRef]

34. Amsterdam Futsal Tournament. Available online: http://www.hirda.org/en/program/sport-peace-dev/hirdaaft/ (accessed on 10 August 2016).

35. HIRDA. Available online: https://www.hirda.org/en/home/ (accessed on 12 December 2019).

36. Five Facts about the Global Somali Diaspora. Available online: http://www.pewresearch.org/fact-tank/2016/ 06/01/5-facts-about-the-global-somali-diaspora/ (accessed on 1 June 2016).

37. UNHCR. Somalia Situation 2017; UNHCR: Geneva, Switzerland, 2017.

38. Bevolking; generatie, geslacht, leeftijd en herkomstgroepering, 1 januari. Available online: http://statline.cbs. $\mathrm{nl} /$ Statweb/publication/?DM=SLNL\&PA=37325\&D1=a\&D2=a\&D3=0\&D4=a\&D5=199\&D6=17-20\&VW=T (accessed on 20 December 2019).

39. van Liempt, I. "And then one day they all moved to Leicester": The relocation of Somalis from the Netherlands to the UK explained. Popul. Space Place 2011, 17, 254-266. [CrossRef]

40. Roble, A.; Rutledge, D. The Somali Diaspora: A Journey Away; University of Minnesota Press: Minneapolis, MN, USA, 2008.

41. Kusow, A.; Bjork, S. From Mogadishu to Dixon: The Somali Diaspora in a Global Context; The Red Sea Press: Trenton, NJ, USA, 2007.

42. Sporton, D.; Valentine, G. Identities on the Move: The Integration Experiences of Somali Refugee and Asylum Seeker Young People; University of Sheffield: Sheffield, UK; University of Leeds: Leeds, UK, 2007.

43. Bigelow, M. (Con)texts for cultural and linguistic hybridity among Somali diaspora youth. New Educ. 2011, 7, 27-43. [CrossRef]

44. Hopkins, G. A changing sense of Somaliness: Somali women in London and Toronto. Gend, Place Cult. 2010, 17, 519-538. [CrossRef]

45. Kay, T. Developing through sport: Evidencing sport impacts on young people. Sport Soc. 2009, 12, 1177-1191. [CrossRef]

46. Mackenzie, C.; McDowell, C.; Pittaway, E. Beyond "do no harm": The challenge of constructing ethical relationships in refugee research. J. Refug. Stud. 2007, 20, 299-318. [CrossRef]

47. The Way Forward: Innovating Diaspora Engagement. Available online: https://www.hirda.org/files/4113/ 9038/6457/background_paper_-_Innovating_diaspora_engagement.pdf (accessed on 24 December 2019).

48. Coalter, F. A Wider Social Role for Sport: Who's Keeping the Score? Routledge: London, UK, 2007.

49. Spaaij, R.; Broerse, J. Sport and the politics of belonging: The experiences of Australian and Dutch Somalis. In Places of Privilege: Interdisciplinary Perspectives on Identities, Change and Resistance; Oke, N., Sonn, C., Baker, A., Eds.; Brill: Leiden, The Netherlands, 2019; pp. 105-122.

50. Dukic, D.; McDonald, B.; Spaaij, R. Being able to play: Experiences of social inclusion and exclusion within a football team of people seeking asylum. Soc. Inclusion 2017, 5, 101-110. [CrossRef]

(C) 2020 by the authors. Licensee MDPI, Basel, Switzerland. This article is an open access article distributed under the terms and conditions of the Creative Commons Attribution (CC BY) license (http://creativecommons.org/licenses/by/4.0/). 